\title{
Pengaruh Karakteristik Individu, Karakteristik Pekerjaan Dan Efikasi Diri Terhadap Kinerja Karyawan (Studi Pada Karyawan Bagian Gudang PT. Hyup Sung Indonesia, Purbalingga)
}

\author{
Panji Candra Setyawan ${ }^{(1)}$ \\ Program Studi Manajemen S1 \\ Fakultas Ekonomi dan Bisnis Universitas Muhammadiyah Purwokerto ${ }^{(1)}$ \\ Email : ${ }^{1}$ Panjicandra91@gmail.com \\ Fatmah Bagis $^{(2)}$ \\ Program Studi Manajemen S1 \\ Fakultas Ekonomi dan Bisnis, Universitas Muhammadiyah Purwokerto ${ }^{(2)}$ \\ Email : ${ }^{2}$ fatmahbagis2014@gmail.com
}

\begin{abstract}
ABSTRAK
Penelitian ini bertujuan untuk mengetahui Pengaruh Karakteristik Individu, Karakterstik Pekejeraan Dan Efikasi Diri Terhadap Kinerja Karyawan Bagian Gudang PT.Hyup Sung Indonesia, Purbalingga. Jumlah populasi penelitian ini sebanyak 108 karyawan. Sampel pada penelitian ini sebanyak 108 karyawan dengan menggunakan teknik sample jenuh. Analisis yang digunakan adalah Uji f, Uji t dan $\mathrm{R}^{2}$ adjusted. Hasil penelitian ini berdasarkan Uji f di peroleh Karakteristik individu, karakteristik pekerjaan dan efikasi diri secara simultan berpengaruh terhadap kinerja karyawan. Hasil penelitian ini berdasarkan uji t diperoleh; (a) Karakteristik Individu berpengaruh positif dan signifikan terhadap kinerja karyawan. (b) Karakteristik Pekerjaan berpengaruh positif dan signifikan terhadap kinerja karyawan. (c) Efikasi Diri berpengaruh positif dan signifikan terhadap kinerja karyawan. Berdasarkan uji koefisien determinasi $\mathrm{R}^{2}$ adjusted menunjukkan besarnya pengaruh Karakteristik Individu, Karakteristik Pekerjaan dan Efikasi Diri terhadap kinerja karyawan sebesar $51,1 \%$, sedangkan sisanya sebesar $48,9 \%$ dipengaruhi variabel diluar model penelitan.
\end{abstract}

Kata Kunci: Karakteristik Individu, Karakteristik Pekerjaan dan Efikasi Diri

\begin{abstract}
This study aims to determine the effect of individual characteristics, work characteristics and self-efficacy on employee performance in the warehouse division of PT. Hyup Sung Indonesia, Purbalingga. The total population of this study were 108 employees. The sample in this study were 108 employees using the saturated sample technique. The analysis used is the $f$ test, $t$ test and R2 adjusted. The results of this study based on the $\mathrm{f}$ test obtained that individual characteristics, job characteristics and self-efficacy simultaneously affect employee performance. The results of this study based on the t-test obtained; (a) Individual characteristics have a positive and significant effect on employee performance. (b) Job characteristics have a positive and significant effect on employee performance. (c) Self-efficacy has a positive and significant effect on employee performance. Based on the coefficient of determination R2adjusted, it shows that the influence of individual characteristics, job characteristics and selfefficacy on employee performance is $51.1 \%$, while the remaining $48.9 \%$ is influenced by variables outside the research model.
\end{abstract}

Keywords: Individual Characteristics, Job Characteristics and Self-Efficacy. 


\section{PENDAHULUAN}

Persaingan dalam dunia usaha semakin kompetitif, perusahaan dituntut untuk dapat mengoptimalkan semua sumber daya yang dimiliki, salah satunya sumber daya manusia mempunyai peran yang sangat besar bagi sebuah organisasi atau perusahaan. Keberhasilan suatu perusahaan tidak hanya tergantung pada peralatan yang modern, sarana dan prasarana yang lengkap tetapi sumber daya manusia yang mendukung. Maka dari itu keberhasilan suatu perusahaan sangat dipengaruhi oleh kinerja karyawan. Setiap perusahaan akan selalu berusaha meningkatkan kinerja karyawan melalui sikap pemimpin yang melibatkan bawahan dalam melaksanakan tugasnya, memberikan kompensasi yang adil dan sesuai dengan hasil kerja karyawan serta pemberian motivasi yang akan meningkatkan kinerja karyawan, sehingga harapan yang menjadi tujuan perusahaan akan tercapai dengan optimal (Gaffar, dkk. 2017).

Manajemen sumber daya manusia sebagaimana dikemukakan oleh Slamet, dkk. (2014), mengatakan bahwa manajemen sumber daya manusia adalah suatu bidang manajemen yang khusus mempelajari hubungan dan peranan manusia dalam organisasi atau perusahaan. Manajemen sumber daya manusia mempunyai pandangan bahwa pegawai dalam suatu perusahaan merupakan asset perusahaan yang perlu dijaga, bukan hanya sebagai faktor produksi saja.

Yulianti (2018) PT. Hyup Sung Indonesia adalah perusahaan yang bergerak pada produksi bulu mata. Perusahaan ini didirikan oleh pengusaha asal negeri Korea yang bernama Mr. Park Noh Jin dan perusahaan ini berlokasi di jalan raya Karangmanyar KM 1, Desa Kalikabong, Kecamatan Kalimanah, Kabupaten Purbalingga, Jawa Tengah. Bulu mata yang diproduksi oleh perusahaan ini merupakan bulu mata yang terbuat dari plastik sintesis yang diimpor langsung dari Korea. Untuk pemasaran produknya, selain di dalam negeri produk ini juga diekspor ke luar negeri seperti Korea, China, Jepang, Turkey, Lebanon, USA, dan Mexico.

Untuk mengedepankan produksi PT. Hyup Sung Indonesia, melakukan peningkatan kualitas produksi, adapun target yang sudah di tetapkan oleh setiap karyawan dalam memproduksi. Keberhasilan perusahaan tersebut dipengaruhi oleh beberapa faktor, salah satu faktor penting adalah sumber daya manusia. Kinerja adalah kesediaan seseorang atau kelompok orang untuk melakukan sesuatu kegiatan dan menyempurnakannya sesuai dengan tanggung jawabnya dengan hasil seperti yang diharapkan, hasil kerja yang dapat dicapai oleh seseorang atau kelompok orang dalam suatu perusahaan sesuai dengan wewenang atau tanggung jawab masing-masing dalam upaya pencapaian tujuan perusahaan secara legal, tidak melanggar hukum dan tidak bertentangan dengan moral atau etika (Mangkuprawira, 2011).

Faktor yang mempengaruhi kinerja karyawan antara lain adalah Karakteristik Individu, Menurut Robbins (2015), dalam mengatakan bahwa "Karakteristik individu mencakup usia, jenis kelamin, tingkat pendidikan, status perkawinan, dan masa kerja dalam organisasi. Sedangkan Menurut James (2012) karakteristik individu adalah minat, sikap dan kebutuhan yang dibawa seseorang didalam situasi kerja. Minat adalah sikap yang membuat seseorang senang akan obyek kecenderungan atau ide-ide tertentu. Sopiah (2010) dalam Daud (2021) mengatakan bahwa karakteristik individu adalah ciriciri biografis, kepribadian, persepsi dan sikap yang dapat mempengaruhi kinerja karyawan.

Dalam penelitian terdahulu R.Handayani. (2016) dengan judul pengaruh karakteristik individu terhadap kinerja karyawan berpengaruh positif signifikan terhadap kinerja karyawan.Aktarina (2019) dengan judul pengaruh karakteristik individu, pekerjaan dan lingkungan kerja terhadap motivasi dan dampaknya terhadap kinerja berpengaruh positif signifikan terhadap kinerja karyawan. 
Selain karakteristik individu yang dapat mempengaruhi kinerja karyawan adalah faktor karakteristik pekerjaan, menurut Hackman dan Oldham dalam Zhou, dkk. (2016), mengungkapkan karakteristik kerja adalah sebuah teori formal yang menggambarkan sejauh mana pentingnya atribut dari pekerjaan dan pengaruh sikap dan tingkah karyawan.

Selain karakteristik individu dan karakteristik pekerjaan, faktor lain yang mempengaruhi kinerja adalah efikasi diri, Menurut Bandura (1997) dalam Subaidi, (2016) efikasi diri adalah keyakinan seorang individu mengenai kemampuannya dalam mengorganisasi dan menyelesaikan suatu tugas yang diperlukan untuk mencapai hasil tertentu. Adapun pendapat lain yang mengungkapkan bahwa efikasi diri adalah keyakinan individu dalam menghadapi dan menyelesaikan masalah yang dihadapinya diberbagai situasi serta mampu menentukan tindakan dalam menyelesaikan tugas atau masalah tertentu sehingga individu tersebut mampu mengatasi rintangan dan mencapai tujuan yang diharapkan (Lunenburg, 2011).

Penelitian ini bertujuan untuk menganalisis pengaruh Karakteristik Individu, Karakteristik Pekerjaan dan Efikasi Diri terhadap kinerja karyawan (studi pada karyawan bagian gudang PT. Hyup Sung Indonesia, Purbalingga).

\section{TINJAUAN PUSTAKA}

\section{Kinerja Karyawan}

Kinerja merupakan hasil kerja yang di capai karyawan dalam mengemban tugas dan pekerjaan yang berasal dari perusahaan. Manthis dan Jackson (2012) menyatakan bahwa kinerja adalah apa yang dilakukan atau tidak dilakukan oleh karyawan dalam mengemban pekerjaanya.Bernadin dan Russel (2011) menyatakan, kinerja merupakan hasil yang di produksi oleh fungsi pekerjaan tertentu atau kegiatan-kegiatan pada pekerjaan tertentu selama periode waktu tertentu. Harsuko (2011) mengatakan, kinerja adalah sejauh mana seseorang telah mengemban tugasnya dalam rangka melaksanakan strategi perusahaan, baik dalam mencapai sasaran khusus yang berhubungan dengan peran karyawan sebagai individu atau dengan memperlihatkan kompetensi yang dinyatakan relevan bagi perusahaan. Kinerja adalah suatu konsep yang multidimensional mencakup tiga aspek, yaitu sikap (attitude), kemampuan (ability), dan prestasi (accomplishment).

\section{Karakteristik Individu}

Thoha, (2012) dalam Sihombing,dkk (2018) Karakteristik individu merupakan pandangan, tujuan, kebutuhan dan kemampuan yang berbeda satu sama lain dari setiap orang. Perbedaan ini akan terbawa dalam dunia kerja, yang akan menyebabkan kepuasan satu orang dengan yang lain berbeda pula, meskipun bekerja ditempat yang sama.

Robbins (2015:), dalam Gaffar, dkk. (2017) mengatakan bahwa, Karakteristik individu mencakup usia, jenis kelamin, tingkat pendidikan, status perkawinan, dan masa kerja dalam organisasi. Selanjutnya menurut Sopiah (2010) mengemukakan bahwa: "Karakteristik individu adalah ciri-ciri biografis, kepribadian, persepsi dan sikap individu".

\section{Karakteristik Pekerjaan}

Hackman dan Oldham (dalam Zhou et al, 2016) dalam Manopo, dkk (2018) mengatakan karakteristik kerja adalah sebuah teori formal yang menggambarkan sejauh mana pentingnya atribut dari pekerjaan dan pengaruh sikap dan tingkah karyawan. Sitio, dkk. (2015) mengungkapkann bahwa karakteristik pekerjaan merupakan bentuk 
karyawan dalam bekerja untuk memotivasi pekerjaannya. Hal ini untuk menumbuhkan semangat kerja tinggi pada karyawan dan lebih produktif karena karakteristik pekerjaan merupakan proses akan membuat suatu pekerjaan tersebut lebih berarti, menantang dan lebih menarik hal ini juga bisa mencegah kebosanan karyawan dari pekerjaan yang monoton sehingga pekerjaan terlihat lebih bervariasi. Karyawan yang memiliki sifat positif terhadap karakteristik pekerjaannya akan semakin berorientasi dibidang pekerjaanya, karyawan akan menekuni dengan konsentrasi dan penuh tanggung jawab disertai perasaan senang sampai diperoleh hasil yang sesuai dan memuaskan seperti yang diinginkan perusahaan, serta memiliki etos kerja tinggi dan akan berusaha semaksimal mungkin untuk mengembangkan diri agar mencapai prestasi tinggi dalam perusahaa.

\section{Efikasi Diri}

Menurut Bandura (1997) dalam Subaidi, (2016) Self-Efficacy adalah keyakinan seorang individu mengenai kemampuannya dalam mengorganisasi dan menyelesaikan suatu tugas yang diperlukan untuk mencapai hasil tertentu. Sedangkan Krintisanti (2015) menyatakan faktor terpenting dalam self-efficacy adalah pengalaman masa lalu Adapun pendapat lain yang mengungkapkan bahwa self efficacy adalah keyakinan individu dalam menghadapi dan menyelesaikan masalah yang dihadapinya diberbagai situasi serta mampu menentukan tindakan dalam menyelesaikan tugas atau masalah tertentu sehingga individu tersebut mampu mengatasi rintangan dan mencapai tujuan yang diharapkan (Lunenburg, 2011). Menurut Luthan (2014) menyatakan bahwa self efficay mengacu pada keyakinan diri mengenai kemampuannya untuk memotivasi sumber daya kognitif dan tindakan yang diperlukan agar berhasil dalam melaksanakan tugas tertentu

\section{METODE PENELITIAN}

Populasi merupakan wilayah generalisasi yang terdiri atas objek/subjek yang mempunyai kualitas dan karakteristik tertentu yang ditetapkan oleh peneliti untuk ditarik kesimpulannya (Sugiyono, 2016). Populasi penelitian ini adalah seluruh karyawan bagian gudang PT. Hyup Sung Indonesia, Purbalingga yang berjumlah 108 karyawan bagian gudang. Sedangkan teknik pengambilan data menggunakan sampling incidental. Teknik pengambilan sampel pada penelitian ini menggunakan sampling jenuh (sensus), yaitu teknik penentuan sampel bila anggota populasi digunakan sebagai sampel.Dengan demikian ukuran sampel yang akan digunakan dalam proses penelitian ini adalah 108 responden.

\section{Definisi Operasional Variabel}

Untuk menyamakan persepsi dalam penelitian ini maka diperlukan adanya definisi operasional variabel yaitu sebagai berikut:

a. Kinerja karyawan Berdasarkan uraian tersebut, kinerja karyawan merupakan perwujudan atas pekerjaan yang telah di hasilkan atau di emban pegawai, Hasil tersebut tercatat dengan baik sehingga tingkat ketercapaian kinerja yang seharusnya dengan apa yang terjadi dapat dievaluasi dengan baik.

b. Karakteristik individu meliputi tentang bagaimana kepuasan seorang individu berbeda dengan individu lainnya itu berbeda. Karakteristik individu mencakup usia, jenis kelamin, presepsi, status dan pendidikan.

c. Karakteristik pekerjaan adalah salah satu bentuk motivasi karayawan dalam bekerja sehingga dapat menumbuhkan semangat tinggi dan lebih produktif dalam bekerja sesuai penugasan dan kebutuhan dalam organisasi atau perusahaan. 
d. Efikasi diri adalah kempuan diri yang dimiliki seseorang untuk memanfaatkan peluang untuk mencapai penyelesaian tugas tertentu dengan berkerja secara efektif dalam berbagai macam situasi yang dihadapi.

\section{Teknik Analisis Data}

Teknik analisis data yang digunakan dalam penelitian ini adalah analisis regresi linear berganda. Analisis regresi berganda merupakan alat untuk menaksir nilai pengaruh dan membuktikan ada tidaknya hubungan kausal antara dua atau lebih variabel independent terhadap satu variabel dependen (Ghazali, 2018). Dalam penelitian ini hubungan antara variabel independent (karakteristik individu,karakteristik pekerjaan dan efikasi diri) dengan variabel dependen (kinerja karyawan).

Uji hipotesis tersebut menggunakan software SPSS karena mampu menghasilkan output yang meyakinkan untuk dianalisis lebih lanjut. Adapun rumus regresi linear berganda berdasarkan (Ghazali, 2018) dapat dirumuskan menjadi :

$$
\mathrm{Y}=\alpha+\beta 1 . X_{1}+\beta 2 . X_{2}+\beta 3 .+\mathrm{e}
$$

Keterangan :

Y : Kinerja Karyawan

$\alpha$ : Konstanta

$\beta$ : Koefisien regresi

$X_{1}$ : Karakteristik individu

$X_{2}:$ Karakteristik pekerjaan

$X_{3}$ : Efikasi diri

e : Standar error

\section{HASIL DAN PEMBAHASAN}

Instrumen dikatakan baik apabila memenuhi dua syarat, yaitu valid dan reliabel. Pengujian validitas instrumen penelitian dilakukan denganmengkorelasikan skor masing -masing indikator dengan skor totalnya dengankriteria jika nilai $r$ hitung $>r$ tabel maka instumen dinyatakan valid dan sebaliknya. Uji reliabilitas data dapat dilakukan dengan melihat nilai Cronbach Alpha. Jika nilai Cronbach Alpha lebih besar 0,70 maka data dinyatakan reliabel (Ghozali, 2018). Hasil uji validitas dan reliabilitas data ditunjukkan pada tabel sebagai berikut:

Tabel 1 Uji Valditas dan reliabilitas Data

\begin{tabular}{|l|c|r|c|}
\hline Variabel & Item & $\begin{array}{c}\text { r- } \\
\text { hitung }\end{array}$ & $\begin{array}{c}\text { Cronbach } \\
\text { Alpha }\end{array}$ \\
\hline Kinerja & 1 & 0.509 & \\
Karyawan & 2 & 0.734 & \\
(Y) & 3 & 0.645 & 0,740 \\
& 4 & 0.714 & \\
& 5 & 0.768 & \\
& 6 & 0.582 & \\
\hline
\end{tabular}




\begin{tabular}{|c|c|c|c|}
\hline Variabel & item & r-hitung & $\begin{array}{c}\text { Cronbach } \\
\text { Alpha }\end{array}$ \\
\hline & 1 & 0.780 & \\
Karakteristik & 2 & 0.764 & \\
Individu(X1) & 3 & 0.756 & 0,761 \\
& 4 & 0,761 & \\
\hline
\end{tabular}

\begin{tabular}{|c|c|c|c|}
\hline Variabel & Item & $\begin{array}{c}\mathrm{r}- \\
\text { hitung }\end{array}$ & $\begin{array}{c}\text { Cronbach } \\
\text { Alpha }\end{array}$ \\
\hline & 1 & 0.407 & \\
2 & 0.691 & \\
Efikasi diri & 3 & 0.695 & \\
(X3) & 4 & 0.580 & \\
& 5 & 0.755 & 0,705 \\
& 6 & 0.534 & \\
& 7 & 0,592 & \\
\hline
\end{tabular}

\begin{tabular}{|c|c|c|c|}
\hline Variabel & Item & $\begin{array}{c}\mathrm{r}- \\
\text { hitung }\end{array}$ & $\begin{array}{c}\text { Cronbach } \\
\text { Alpha }\end{array}$ \\
\hline & 1 & 0.741 & \\
Karakteristik & 2 & 0.686 & \\
pekerjaan (X2) & 3 & 0.808 & 0,713 \\
& 4 & 0,697 & \\
\hline
\end{tabular}

Sumber: data primer diolah, 2021

Berdasarkan tabel diatas terlihat bahwa semua indikator mempunyai nilai $\mathrm{r}$ hitung > r-tabel $(0,1535)$ dan nilai Cronbach alpha > 0,70 sehingga dapat disimpulkan bahwa semua indikator yang digunakan dalam penelitian ini valid danreliabel.

\section{Uji Normalitas Data}

Berdasarkan uji normalitas data menunjukkan bahwa besarnya nilai Kolmogorov-Smirnove didapatkan hasil Asymp. Sig. (2-tailed) adalah 0,802 >0,05 yang dapat diartikan bahwa data berdistribusi normal.

\section{Uji Multikolineartias dan Heteroskedastisitas}

Agar diperoleh hasil estimasi yang terbaik dan tidak bias (Best Linier Unbiased Estimation) maka dilakukan uji asumsi klasik, diantaranya yang dilakukan dalam penelitian ini adalah uji Multikolonieritas dan uji Heteroskedastisitas.

Uji multikolinearitas digunakan untuk menguji apakah model regresi ditemukan adanya korelasi antara variabel bebas (independen). Modelregresi yang baik seharusnya tidak terjadi korelasi antara variabel independen. Untuk mengetahui ada tidaknya multikolinearitas maka dapat digunakan dengan menganalisa dan melihat nilai dari Variance Inflation Faktor (VIF) dan tolerance dari variabel independen yang terpilih yang tidak dijelaskan oleh variabel independen lainnya. Nilai cut off yang dipakai untuk mengetahui adanya multikolinearitas adalah nilai tolerance $\geq 0,10$ atau VIF $\leq 10$ (Ghozali, 2018). Uji Heteroskesdatisitas bertujuan untuk menguji apakah dalam model regresi terjadi ketidaksamaan variabel dari residual satu pengamatan ke pengamatan yang lain. Jika variabel dari residual satu pengamatan ke pengambilan lain tetap, maka disebuthomoskedastisitas dan jika berbeda disebut heteroskedastisitas. Cara 
menguji ada tidaknya heteroskedastisitas, yaitu dengan menggunakan uji glejser. Model regresi yang baik adalah homokesdastisitas atau tidak terjadi heteroskesdastitas. Heteroskesdastitas terjadi jika nilai sig. $<5 \%$, apabila nilai sig. $>0,05$ maka tidak terjadi heteroskesdatisitas (Ghozali, 2018).

Tabel 2 Uji Multikolinearitas dan Heteroskedastisitas.

\begin{tabular}{|c|c|c|c|c|}
\hline \multirow{2}{*}{$\begin{array}{c}\text { Variabel } \\
\text { Bebas }\end{array}$} & \multicolumn{2}{|c|}{$\begin{array}{c}\text { Uji } \\
\text { Multikolinearitas }\end{array}$} & \multicolumn{2}{c|}{$\begin{array}{c}\text { Uji } \\
\text { Heteroskedast } \\
\text { isitas }\end{array}$} \\
\cline { 2 - 5 } & Tolerance & VIF & t & Sig \\
\hline $\begin{array}{c}\text { Karakteristik } \\
\text { individu }\end{array}$ & 0.519 & 1.927 & 0.279 & 0.781 \\
\hline $\begin{array}{c}\text { Karakteristik } \\
\text { pekerjaan }\end{array}$ & 0.700 & 1.428 & 0.131 & 0.896 \\
\hline Efikasi diri & 0.557 & 1.795 & 1.050 & 0.296 \\
\hline
\end{tabular}

Sumber: data primer diolah 2021

Berdasarkan table di atas menunjukkan semua variabel bebas memberikan nilai VIF $<10$ dan nilai Tolerance $>0,1$ sehingga dapat disimpulkan model dalam penelitian ini bebas dari penyimpangan asumsi klasik Multikolinieritas. Demikian juga hasil uji heteroskedastisitas pada Tabel menunjukkan bahwa semua variabel bebas memberikan nilai sig. > 0.05 yang berarti model bebas dari penyimpangan asumsi klasik Heteroskedastisitas.

\section{Analisis Regresi Linier Berganda}

Untuk mengetahui pengaruh variabel bebas terhadap variabel terikat dilakukan dengan analisis regresi linier berganda. Hasil analisis regresi linier berganda penelitian ini disajikan pada Tabel 3 sebagai berikut:

Tabel 3 Hasil Persamaan Regresi

\section{Coefficients $^{\mathrm{a}}$}

\begin{tabular}{|l|r|r|l|r|r|}
\hline \multirow{2}{*}{ Model } & \multicolumn{2}{|c|}{$\begin{array}{l}\text { Unstandardized } \\
\text { Coefficients }\end{array}$} & $\begin{array}{c}\text { Standardize } \\
\mathrm{d} \\
\text { Coefficients }\end{array}$ & \multirow{2}{*}{$\mathrm{T}$} & \multirow{2}{*}{ Sig. } \\
\cline { 2 - 4 } & \multicolumn{1}{|c|}{$\mathrm{B}$} & $\begin{array}{c}\text { Std. } \\
\text { Error }\end{array}$ & Beta & & \\
\hline (Constant) & .856 & .340 & & 2.515 & .013 \\
Karakteristik & .252 & .084 & .282 & 3.003 & .003 \\
Individu & .314 & .068 & .371 & 4.589 & .000 \\
Karakteristik & .237 & .100 & .215 & 2.370 & .020 \\
Pekerjaa & & &
\end{tabular}

Dependent Variable: Kinerja Karyawan

Sumber: data primer diolah, 2021 
Berdasarkan hasil analisis regresi berganda diatas, dapat disusun persamaan regresi sebagai berikut :

$\mathrm{Y}=\alpha+\beta 1 \mathrm{X}_{1}+\beta 2 \mathrm{X}_{2}+\beta 3 \mathrm{X}_{3}$

$Y=0,856+0,252 X_{1}+0,314 X_{2}+0,237 X_{3}$

Persamaan regresi tersebut diatas dapat dijelaskan sebagai berikut :

$\alpha=$ Nilai konstanta $(\alpha)$ menunjukan nilai positif sebesar 0,856 menyatakan bahwa apabila karakteristik individu, karakteristik pekerjaan, efikasi diri tidak ada perubahan maka nilai kinerja karyawan sebesar 0,856 satuan.

$\beta 1=$ Nilai koefisien regresi variabel karakteristik individu menunjukkan nilai positif sebesar 0,252 meyatakan bahwa setiap peningkatan karakteristik individu sebesar 1 satuan maka akan terjadi kenaikan nilai kinerja karyawan sebesar 0,252 satuan dengan asumsi variabel lain tetap.

$\beta 2=$ Nilai koefisien regresi variabel karakteristik pekerjaan menunjukkan nilai positif sebesar 0,314 menyatakan bahwa setiap peningkatan karakteristik pekerjaan sebesar 1 satuan maka akan terjadi kenaikan nilai kinerja karyawan sebesar 0,314 satuan dengan asumsi variabel lain tetap.

$\beta 3$ = Nilai koefisien regresi variabel efikasi diri kerja menunjukkan nilai positif sebesar 0,237 bahwa setiap peningkatan efikasi diri sebesar 1 satuan maka akan terjadi kenaikan nilai kinerja karyawan sebesar 0,237 satuan dengan asumsi variabel lain tetap.

$\mathrm{e}=$ standar kesalahan error.

Berdasarkan analisis uji linear berganda maka terlihat bahwa variabel yang mempunyai pengaruh terbesar terhadap kinerja karyawan bagian gudang pada PT. Hyup Sung Indoneisa, Purbalingga adalah variabel karakteristik pekerjaan karena nilai koefisien variabel karakteristik pekerjaan adalah terbesar yakni 0,314. Kemudian disusul oleh variabel karakteristik individu dengan nilai koefisien sebesar 0,252, dan variabel Efikasi diri sebesar 0,237. Berdasarkan hasil analisis regresi linier berganda, maka variabel yang paling berpengaruh terhadap kinerja karyawan PT. Hyup Sung Indonesia adalah karakteristik pekerjaan, karena nilai $\beta$ dari karakteristik pekerjaan paling besar yaitu 0,314 disusul oleh karakteristik individu dengan nilai 0,252 dan efikasi diri 0,237.

\section{Uji Koefisien Determinasi $\left(\mathbf{R}^{\mathbf{2}}\right)$}

Koefisien determinasi $\left(\mathrm{R}^{2}\right)$ digunakan untuk mengukur seberapa jauh kemampuan model dalam menerangkan variasi variabel dependen. Nilai koefisien determinasi adalah antara nol dan satu. Berikut ini hasil analisis korelasi ganda koefisien determinasi pada penelitian ini dapat dilihat pada tabel 7 sebagai berikut: 
Tabel 4 Hasil Nilai Koefisien Determinasi Persamaan

\begin{tabular}{|l|r|}
\multicolumn{1}{|c|}{ Model Summary } \\
\hline Model & 1 \\
\hline R Square & .724 \\
\hline Adjusted R Square & .525 \\
\hline Std. Error of the Estimate & .511 \\
\hline Sut & .22214 \\
\hline
\end{tabular}

Sumber: data primer diolah, 2021

Dari tabel di atas dapat dilihat nilai Adjusted $\mathrm{R}^{2}$ model regresi yang terbentuk dalam penelitian ini adalah sebesar 0,511 yang menunjukan bahwa kemampuan variabel independen karakteristik individu, karakteristik pekerjaan dan efikasi diri dalam menjelaskan variabel dependent adalah sebesar 51,1\% Kinerja karyawan dan sisanya $48,9 \%$ dijelaskan oleh variabel lain yang tidak termasuk dalam model penelitian ini.

\section{Uji Kecocokan Model (Uji F)}

Uji F digunakan untuk menguji ketetapan model regresi atau goodness of fit, apakah persamaan yang berbentuk masuk dalam kriteria cocok (fit) atau tidak. Hasil uji $\mathrm{f}$ untuk kedua persamaan regresi sebagai berikut ini:

1) Uji Kecocokan Model (Uji F)

Dari hasil uji $\mathrm{f}$ dapat dilihat dari Fhitung pada tabel ANOVA yaitu diperoleh penentuan daerah kritis dengan keyakinan $95 \%$ atau $(\alpha=0,05)$. Hasil analisis uji $\mathrm{f}$ dapat dilihat pada tabel 4.28:

Tabel 5 Hasil Uji F Model

\begin{tabular}{|c|c|c|c|c|c|}
\hline Model & $\begin{array}{c}\text { Sum of } \\
\text { Squares }\end{array}$ & df & $\begin{array}{c}\text { Mean } \\
\text { Square }\end{array}$ & F & Sig. \\
\hline $\begin{array}{c}\text { Regression } \\
\text { Residual } \\
\text { Total }\end{array}$ & 5.663 & 3 & 1.888 & 38.257 & $.000^{\mathrm{b}}$ \\
10.795 & 104 & .049 & & \\
\hline
\end{tabular}

a. Dependent Variable: KINERJA KARYAWAN

b. Predictors: (Constant), Karakteristik Pekerjaan,

Karakteritik Individu, Efikasi Diri

Sumber: data primer diolah, 2021

Dari tabel diatas dapat nilai $\mathrm{F}$ hitung adalah 38,257 dengan nilai signifikansi 0,000 sedangkan $\mathrm{F}$ tabel pada tingkat kepercayaan $95 \%, \mathrm{df}=\mathrm{n}-\mathrm{k}-1=108-4$ adalah sebesar 2,69. Dengan demikian F hitung > F tabel $(38,257>2,649)$. Maka, dapat disimpulkan uji hipotesis pertama menyatakan bahwa terdapat pengaruh secara simultan antara Karakteristik Individu, Karakteristik Pekerjaan dan Efikasi Diri terhadap Kinerja karyawan. Ho ditolak dan Ha diterima. 


\section{Uji t (Uji Statistic Parsial)}

Uji statistik $\mathrm{t}$ digunakan untuk mengetahui pengaruh masing-masing variabel independen terhadap variabel dependen (Ghozali, 2018).

2) Karakteristik individu berpengaruh positif signifikan terhadap kinerja karyawan Berdasarkan hasil analisis diperoleh $\mathrm{t}$ tabel dengan signifikansi $0,05(\mathrm{df}=\mathrm{n}-\mathrm{k}=108-$ $4=105$ ) maka t tabel sebesar 1,659 dikarenakan sig 0,003 <0,05 dan t hitung 3,003 > t tabel 1,659 artinya variabel karakteristik individu berpengaruh positif signifikan terhadap kinerja karyawan PT.Hyup sung Indonesia,Purbalingga,Studi pada karyawan bagian gudang sehingga Ha diterima dan Ho ditolak

3) karakteristik pekerjaanberpengaruh positif signifikan terhadap Kinerja karyawan.

Berdasarkan hasil analisis diperoleh $\mathrm{t}$ tabel dengan signifikansi 0,05 $(\mathrm{df}=\mathrm{n}-\mathrm{k}=108-3$ $=105)$ maka $\mathrm{t}$ tabel sebesar 1,659 dikarenakan sig 0,000<0,05 dan $\mathrm{t}$ hitung 4,589 > $\mathrm{t}$ tabel 1,659 artinya variabel karakteristik pekerjaan berpengaruh positif signifikan terhadap kinerja karyawan pada PT,Hyup sung Indonesia,Purbalingga,Studi pada karyawan bagian gudang. sehingga Ha diterima dan Ho ditolak.

4) Efikasi diri berpengaruh positif signifikan terhadap Kinerja karyawan. Berdasarkan tabel 4.21 diperoleh $\mathrm{t}$ tabel dengan signifikansi $0,05(\mathrm{df}=\mathrm{n}-\mathrm{k}=108-3=$ 105) maka $t$ tabel sebesar 1,659 dikarenakan sig $0,002<0,05$ dan $t$ hitung 2,852 $>\mathrm{t}$ tabel 1,659 artinya variabel efikasi diri berpengaruh positif signifikan terhadap kinerja karyawan PT,Hyupsehingga Ha diterima dan Ho sung Indonesia, Purbalingga, studi pada karyawan bagian gudang. ditolak.

\section{SIMPULAN, KETERBATASAN DAN SARAN}

\section{Simpulan}

Berdasarkan analisis data dan pembahasan yang telah dilakukan makadapat ditarik kesimpulan sebagai berikut:

1. Karakteristik individu, karakteristik pekerjaan dan efikasi diri secara simultan berpengaruh terhadap kinerja karyawan

2. Karakteristik Individu secara parsial berpengaruh positif dan signifikan terhadap kinerja karyawan

3. Karakteristik Pekerjaan secara parsial berpengaruh positif dan signifikan terhadap kinerja karyawan

4. Efikasi Diri secara parsial berpengaruh psositif dan signifikan terhadap kinerja karyawan

\section{Keterbatasan}

Keterbatasan dalam penelitian ini adalah:

1. Sampel yang digunakan dalam penelitian ini hanya 108 responden, sehingga tidak menutup kemungkinan akan di peroleh hasil yang berbeda jika penelitian tidak di satu bagian saja sehingga akan lebih banyak jumlah sampel yang diteliti dan menyarankan meneliti variabel lain.

\section{Saran}

Berdasarkan penulisan penelitian ini, peneliti menyadari masih terdapat banyak kekurangan didalamnya. Saran dari peneliti adalah sebagai berikut:

1. Bagi Perusahaan:

a) Dari hasil uji statistik descriptive nilai mean pada variabel karakteristik individu 
yaitu 4,27 > 4 yang artinya sudah baik maka variabel karakteristik pekerjaan di PT. Hyup sung Indonesia, Purbalingga patut di kembangkan lagi agar bisa lebih lagi untuk kedepannya bagi perusahaan yang pada akhirnya karakteristik individu akan berpengaruh terhadap kinerja karyawan.

b) Dari hasil uji statistik descriptive nilai mean pada variabel karakteristik pekerjaan yaitu 4,05> 4 yang artinya sudah baik tetapi disarankan agar perusahaan bisa lebih sering mengadakan pelatihan agar bisa meningkatkan karakteristik pekerjaan sehingga dapat mengoptimalkan kinerja karyawannya.

c) Dari hasil uji statistik descriptive nilai mean pada variabel Efikasi diri yaitu 4,30 > 4 yang artinya sudah baik maka variabel efikasi diri di PT. Hyup sung Indonesia, Purbalingga patut di pertahankan yang pada akhirnya efikasi diri akan berpengaruh terhadap kinerja karyawan.

2. Karakteristik Individu, Karakteristik Pekerjaan dan Efikasi Diri yang terdapat pada karyawan bagian gudang di PT. Hyup Sung Indonesia memiliki pengaruh sebesar 0,511 atau 51,1\% terhadap Kinerja karyawan dan sebesar 0,489 atau 48,9\% dipenaruhi oleh variabel lain. Oleh karena itu, perlu diadakan penelitian lanjutan untuk mengeksplorasi variabel lainnya yang dapat mempengaruhi kinerja karyawan pada gudang pada PT. Hyup Sung Indonesia seperti seperti disiplin kerja dan pelatihan kerja.

\section{DAFTAR PUSTAKA}

Ananda, selvia, sella ; Sunuharyon, swasto, Bambang 2018. Pengaruh karakteristik individu, karakteristik pekerjaan terhadap kinerja karyawan PT Petrokimia dengan variabel mediator motivitas kerja karyawnan. Surabaya. Fakultas ilmu administrasi. Fakultas ilmu administrasi universitas brawijaya. Vol.58 No 1, mei 2018. ISSN: 2541-187.

Astutik, mardi, dkk 2020. Pengaruh karakteristik pekerjaan terhadap kinerja karyawan dan kepuasan kerja dengan variable moderator budaya kerja pada badan keswadayaan masyarakat (BKM) di kota Probolinggo. Vol, 17 No. 1, Mei 2020.ISSN 2442-8604.

Bandura, Albert. (1997). Self-Efficacy The Excercise of Control. USA: W. H Freeman and Company.

Dharma,Robby. 2018. Pengaruh Lingkungan Kerja Dan Karakteristik Pekerjaan Dan Motivasi Terhadap Kinerja Karyawan Pada Bank Mega Syariah Cabang Padang. Universitas Putra Indonesia YPTK Padang. Majalah Ilmiah, Vol. 25, No. 1, Maret.

Daud,Greis M.Sendow,dkk (2021). Pengaruh Karakteristik Individu, Kepribadian, Dan Pengembangan Sumber Daya Manusia Terhadap Kinerja Karyawan Di Pt. Industri Kapal Indonesia (Persero) Unit Dok Dan Galangan, Bitung. Jurnal EMBA Vol.9 No.2 Aprpil 2021, ISSN 2303-1174.

Fadilah, Hubbil,Laila ; S, Laura Netty 2018. Pengaruh Self Efficacy Dan Empowerment Terhadap Kinerja Karyawan Dengan Budaya Organisasi Sebagai Variabel Moderating Pada Pt.Taman Impianjaya Ancol . Program narotStudi Manajemen Fakultas Ekonomi dan Bisnis Universitas 17 Agustus 1945 Jakarta. Media Manajemen Jasa ISSN 2502-3632 (Online) ISSN 2356-0304 (Paper) Vol.6 No.1, Januari - Juni 2018.

Hidayat, herman dan Setiawan aries ivan 2016. Pengaruh self esteem dan self efficacy terhadap kinerja karyawan Studi pada karyawan PT tomo food industri, sumedang. Jurnal sains manajemen \& akuntansi Volume No. 2/ November /2016. 
Johari, Johanim dan Yahya, kirana, khaulida 2009. Linking organizational structure, Job characteristics, and job performance constructs: A proposed framework. Vol, 4, No. 3 march 2009.

Kadek Dwiyani, Ciptana Putri , Maria Mediatrix Ratna Sari, I Wayan Ramantha, I Gusti Ayu Nyoman Budiasih. 2019. Effect Of Self-Efficacy, Competence And Compensation In Performance Of Financial Manager On Motivation As Moderation. Faculty Of Economic \& Business Udayana University , Bali ,Indonesia. Vol. 6 No. 3, May 2019, Pages: 83 93

Kharismatuti, N. (2012). Pengaruh Kompetensi dan Independensi Auditor Terhadap Kualitas Audit dengan Etika Auditor Sebagai Variabel Pemoderasi. Universitas Diponegoro.

Narorrama, hendra, i, gde dan Surya ketut Bagus ida 2015. Pengaruh karakteristik pekerjaan dan kompensasi finansial terhadap kepuasan dan kinerja karyawan pada koperasi pegawai negeri kamadhuk RSUP. Fakultas ekonomi dan bisnis Universitas Udayana, Bali Indonesia. E-jurnal manajemen Unud, Vol.4 , No.12, 2015: 4302-4334. ISSN: 2302-8912

Sapta Rini Widyawati,I Wayan Sujana, I Wayan Sukadana .2018. The Role of Work Motivationin Mediating the Effect Self Esteemand Self Efficacy on Employee PerformanceatCV.Alam Tanpaka, Denpasar Bali. Faculty of Economics, University of Mahasaraswati Denpasar. Vol. 9, Issue. 11, Page no: ME 21138-21147

Saraswaty, Emyliana, Ulfie ; Lestari, ningsih. 2018. Pengaruh self efficacy, dan compensation terhadap kinerja karyawan PT. Sumber alfaria trijaya. Sekolah tinggi ilmu ekonomi indonesia (STIESIA), Surabaya. Jurnal ilmu dan riset manajemen. Volume 7, Nomor 12, Desember 2018. ISSN : 2461-0593.

Sari, Permata, Desi ; Candra, Yeki 2020. Pengaruh pengembangan karir, self efficacy dan motivasi kerja terhadap kinerja karyawan. Fakultas Ekonomi dan Bisnis Universitas Putra Indonesia "YPTK" Padang. Volume 1, Issue 3, Januari 2020. E-ISSN : 26865238, P-ISSN : 2686-4916.

Simanjuntak, Hellen, Vera 2018. Pengaruh Job Embeddednes Dan Komitmen Organisasi Serta Kepribadian Terhadap Kepuasan Kerja Pegawai Dan Kinerja Pegawai Pada Universitas Trunajaya Bontang Kinerja 15 (2), 2018 82-99.

Sihombing, Parlindungan, Eko dkk 2018. Pengaruh karakteristik individu, karakteristik pekerjaan, dan self efficacy terhadap kinerja karyawan pada PT. PLN (persero) rayon Manado Selatan. Fakultas Ekonomi dan Bisnis, Jurusan manajemen Universitas Sam Ratulangi Manado. Vol.6 No,4 September 2018, hal 2858-2867. ISSN: 2303-1174.

Sito, Alexander, dkk 2015. Pengaruh karakteristik pekerjaan, budaya organisasi dan kualitas interaksi atasan dan bawahan terhadap kinerja melalui perilaku bekerja karyawan di PTPN Surabaya. Fakultas Ekonomi Universitas Jember. Vol. 9, No 2 Juli 2015 hal 160-173.

Subaidi, agus 2016. Self efficacy siswa dalam pemecahan masalah matematika. Universitas madura. Volume 1, Nomor 2, Maret 2016.

Sugmawati, Dwi; Afrianty, wulida, tri 2018. Pengaruh self efficacy terhadap in-role performance karyawan dengan motivasi kerja sebagai variabel moderator Studi pada karyawan Banck Central Asia KCU Borrobudur Malang. Jurnal administrasi Bisnis (JAB)Vol. 61 No. 4 agustus 2018.

Sugiyono. 2015. Metode Penelitian Pendidikan: Pendekatan Kualitatif, Kuantitatif dan R\&D. Bandung: ALVABETA, cv. 
Widyawati ,Rini, Septa ; Karwini ,Ketut, Ni. 2018. Pengaruh Self Esteem, Self Efficacy dan keterlibatan kerja terhadap kinerja karyawan terhadap kinerja karyawan pada PT. Dwi Fajar Semesta Denpasar. Forum Manajemen, Volume 16, Nomor 2, Tahun 2018 
